Fecha de recepción: mayo 2014 Fecha de aceptación: mayo 2015 Versión final: julio 2016

\section{La seducción del cuerpo vestido en La fuente de las mujeres}

Lucia Acar *

Resumen: Estamos acostumbrados a pensar en la seducción del cuerpo femenino desde la desnudez. La poca o ninguna ropa es una recurrencia en la construcción de la imagen de la mujer seductora. Las tiras del vestido crean una relación frenética entre la piel y la tela representando los deseos, intenciones y sentimientos, contribuyendo a la concepcion plástica de una película. Los cuerpos femeninos en La fuente de las mujeres, una película de cineasta rumano Radu Mihaileanu, son vestidos y no quieren dejarse seducir por la desnudez, sino en virtud de una huelga de sexo, lo que provoca una revolución en un pequeño pueblo de comunidad machista y ultra conservadora.

Palabras clave: cuerpo - femenino - plasticidad - seductor - traje.

[Resúmenes en inglés y portugués en la página 104]

${ }^{(*)}$ Doctoranda en Sociología - IUPERJ/UCAM. Maestra en Ciencia del Arte - UFF. Profesora y Coordinadora del Postgrado en Artes Visuales - UNESA. Investigadora de Moda y Consejera del Instituto Zuzu Angel - IZA. Miembro del Comité de Honor del Diseño Latinoamericano y del Comité Editorial de la Facultad Diseño y Comunicación de la Universidad de Palermo, en Buenos Aires.

Estamos acostumbrados a pensar en la seducción del cuerpo femenino de la desnudez. La poca o ninguna ropa es una recurrencia en la construcción de la imagen de la mujer que quiere seducir. El vestuario, vestido o desvestirse que ayuda a la atmósfera de audacia y ánimo en las representaciones cinematográficas, desesperadamente tratando de crear una relación entre la piel y el tejido que anhela encontrar el ojo del espectador. El traje viene a representar los deseos, intenciones y sentimientos, contribuyendo al diseño de una película de plástico.

Sin ser ajeno a las metamorfosis del cuerpo, los comportamientos, las representaciones estéticas de épocas históricas, el traje es un diseño gráfico que se destina directamente al cuerpo y "lleva" el personaje que representa, con elementos visuales que van desde piezas ropa de las máscaras, accesorios, cabello y maquillaje. Buscar un enfoque posible a la verdad escénica que quiere comunicar. 
En La fuente de las mujeres, una película del cineasta rumano Radu Mihaileanu, cuerpos femeninos se visten y no quiere dejarse seducir por la desnudez, pero la fuerza de una huelga de sexo, lo que provocó una revolución en una pequeña aldea habitada por un macho comunidad y ultra conservadora.

La guerra de los sexos, un tema difícil para los tiempos que corren, no es nueva y se remonta a la comedia griega de Aristófanes Lisístrata, representada en 411 a.c. Cansado de una guerra que ha durado 20 años, las mujeres de Atenas, Esparta de Beocia y Corinto (ciudades griegas más afectados por la guerra), encabezada por los atenienses Lisístrata, decidió poner fin a las hostilidades con una táctica poco ortodoxa: ¡una huelga de sexo! La forma en que se construye la narrativa de las mujeres de origen, la historia se convierta actual e interesante, ya que actualiza un tema ya tensas por la película sexista con humor y las tradiciones que cuestionan, presentando de una manera respetuosa y poéticas costumbres de una comunidad Turquía, por cierto, que, lejos de ignorar las costumbres sólo cuestionaron.

Centrado en la guerra de los sexos, esta comedia dramática es una fábula moderna de un pequeño pueblo donde las mujeres amenazan los hombres se niegan a tener relaciones sexuales con su pareja, con la intención de llamar la atención sobre las condiciones de vida y trabajo social, y el hogar. La trama está inspirada en un hecho reciente registrada en Turquía, donde las mujeres musulmanas no se ve en la vida cotidiana es una forma correcta de vivir. Ellos hacen el trabajo pesado, en busca de agua a la aldea donde viven, mientras que los hombres pasan su día bebiendo té y jugando a las cartas, y de ser una mera reproducción. Se valoran por el don de la maternidad, pero de ninguna manera dejar el trabajo de campo, origen de las lesiones físicas y emocionales durante el transcurso de la captación de agua. Cuando Leila, interpretado por Leila Bekhti, sugiere una huelga de amor (léase sexo) que los hombres se dan cuenta de que el valor de los compañeros no sólo en los servicios domésticos, es la introducción de una revolución en el pueblo y la gente tiene que hacer frente a lo que el Corán dice y se supone que esta nueva realidad femenina.

En la película, los trajes firmados por Viorica Petrovich, traje diseñador rumano que trabaja para la ópera, el teatro y el cine, y ganó el premio a los mejores regalos del diseño del traje de una característica diferente de lo que se espera de una acción que tiene como objetivo utilizar el cuerpo como un instrumento de persuasión. En general, lo que veríamos sería una visión generosa del cuerpo reveló y no oculta. En una guerra de los sexos, donde el cuerpo de la mujer es un arma para lograr los objetivos, el equipo tendría un papel muy importante en la construcción de un lenguaje visual de la seducción y el deseo.

La adherencia al cuerpo es sin duda la ropa más evidentes: envase que oculta y revela y oculta simula. Físicamente autónoma, es, sin embargo, estrechamente relacionada con la entidad que recibe el calor y los olores, y que ofrece un estatuto. La cortina de tela cortada o se convierte en una imagen en el momento en que se viste (Villaça, 2007).

La imagen de la película muestra un vestido de cuerpo de la mujer que no quiere ser seducido por la apariencia, sino que quiere garantizar el orden y reclamar una relación de 
igualdad con el hombre haciéndose pasar por agente y fuente de una delicada fuerza que quiere transformar la vida social de comunidad machista y prejuiciosa.

En la película, el traje tiene una característica diferente de lo que se espera de una acción que tiene como objetivo utilizar el cuerpo como instrumento de persuasión. Y en una guerra de los sexos, donde el cuerpo femenino se convierte en un arma para lograr los objetivos, la ropa debe tener un papel muy importante en la construcción de un lenguaje visual de la seducción y el deseo.

La representación del cuerpo femenino, desde la construcción de los trajes que busca expresar conceptos y crear un ambiente de arte y estética, en última instancia, se unan en una identidad cultural que se expresa a través de la ropa y los accesorios, que son capaces de multiplicarse sentidos y las ideologías y críticas expresas.

Como fenómeno cultural de la modernidad, la moda va más allá del cuerpo, tal vez su primer espacio de presentación, y se dirige hacia la cultura a través de prácticas y comportamientos, expresados en forma de usos, costumbres y actitudes, con el fin de constituir una representación social importante que se manifiesta como una expresión coloquial, urbano y social.

La historia de la ropa como un estudio de la ropa y el cuerpo en contextos culturales específicos encuentra terreno fértil en el cine.

La sinergia de la industria de la moda con las industrias de la comunicación, el entretenimiento y la cosmética llevó a una explosión de la moda procedimientos, lo que influyó en el sentido de las prácticas de consumo, estilos de vida, y la identificación de los individuos con ciertos productos.

En La fuente de las mujeres, además de las formas tradicionales de manipulación y señales que refuerzan momentos y situaciones, también no queda fuera del elemento de merchandising que el cine sabe tan bien explorar cuando está en medio de una comunidad aislada que brilla el diseñador de una empresa casquillo de los deportes en el campesino.

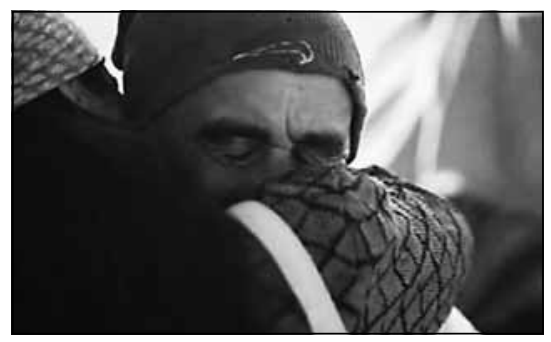

Figura 1. La fuente de las mujeres. Fuente. Radu Mihaileanu, 2011.

La industria del cine tiene un gran potencial para los negocios, también funciona como una pasarela de moda en trajes son creados por famosos diseñadores, como: Givenchy en 
Funny Face, Yves Saint Laurent Belle de Jour, Armani y Ralph Laurent resistente Woody Allen en Novio neurótico, novia nerviosa, que funciona como un gran escaparate de consumo. Sólo recuerda el reciente éxito de Sex and the City" donde Carrie Bradshaw (Sarah Jessica Parker) "vende" todo lo que orbita alrededor o debajo de su cuerpo.

El libro What Money Can't Buy, The Moral Limits of Markets del filósofo de Harvard Michael Sandel, presenta un escenario muy atractivo en el que los mercados actúan como principales invasores de comercial contemporánea, señalando una tendencia que en su interpretación tiene una más bien aspecto negativo:

En las últimas tres décadas, se ha pasado de una economía de mercado a una sociedad de mercado. La economía de mercado es una herramienta para la organización de una actividad productiva. Sin embargo, una sociedad de mercado es un lugar donde todo está a la venta, en la que los valores de mercado rigen todos los aspectos de la vida (Sandel, 2012, p. 36).

Este cambio en la vida social de las personas promueve la ampliación de las concepciones y prácticas cívicas que las relaciones se establecen a partir de los comportamientos comerciales influenciadas por la lógica del mercado. Al subcontratar a guerras contratistas privados y cuando tenemos colas separadas para las reglas de seguridad en los aeropuertos, y son más bajos para aquellos que pueden permitírselo, el resultado es que la vida se divide y se erosiona instituciones se acercan las clases sociales y espacios públicos que forjan un sentido de experiencia común y ciudadanía compartida.

La pérdida de los espacios comunes y compartidos, donde las diferentes clases son en la vida diaria, no la promoción de una sociedad inclusiva y justa, sino que produce ciudadanos que están separados por diferentes estratos sociales y una "mercantilización de la vida pública." Hay una necesidad urgente de repensar el papel de los mercados, que en lugar de separar debe estar comprometido con la creación de instituciones que promueven el enfoque de las clases. Sandel llega a la conclusión de que la democracia no es una "igualdad perfecta", pero la posibilidad de una vida compartida en la que se negocian y se respeten las diferencias.

A democrático e inclusivo es el deseo de la gran mayoría de las personas. Pero para que esto sea implementado es entender los mecanismos que rigen los procesos sociales, donde es posible darse cuenta de que la moda puede fomentar mecanismos como la declaración, donde los individuos y grupos sociales imitan y se diferencian a través de prácticas prendas de vestir, así como ser una poderosa fuente de estímulos para el consumo.

En este nuevo modelo de "sociedad de mercado" de la moda es sin duda uno de los agentes facilitadores, porque su dinámica de socialización permite que el sentimiento de inclusión y la igualdad lograda con la adopción de miradas que hacen apariciones sociales, y son construidos por los individuos en su estrategias de socialización y estado.

El vestuario, a su vez, ayuda a construir este escenario donde los deseos, órbita y proyecciones en las imágenes de la moda será el cambio de conceptos, comportamientos y apariencias que homogenizan lugares y personas distantes, pero al mismo tiempo despiertan características y lugares únicos. 
La nueva corporeidad, además de ser un factor social que promueve un vínculo sutil entre el individuo y el mundo, se presentan como una cultura de las apariencias que alberga las experiencias urbanas que crean nuevos individuos y espacios sociales (Villaça, 2012, p. 88). Hay más grandes héroes y líderes que ejercen encanto, pero los héroes mediáticos que vienen construidas por una lógica de mercado, frente a una comunicación inmediata, la difusión de actitudes y gestos que ayuden a construir las singularidades globalizados. Estos nuevos héroes no son de larga duración, pero efímero como la moda, tiene que ser renovado cada temporada y provocar nuevas afinidades y tendencias.

La visibilidad y el rendimiento como las marcas actuales, más modelos y abolición de las reglas sociales que se convierten en variables y se sustituyen por una autonomía de la persona que busca su propio reconocimiento, una cultura que fomenta el auto para ser los propios empresarios búsqueda del éxito y la visibilidad, con la consiguiente suspensión de certeza es que la película la relación y de la moda de una gran variedad de posibilidades y el cumplimiento que los individuos hagan uso de la posibilidad de editar, seleccionar lo que es relevante o no, a través de sus documentos de identidad y opciones ... ¡ Un comisariado esencial y fundamental!

El cuerpo de la mujer en el cine, que transforma el sabor de la tecnología, crea una narrativa cinematográfica seductora. Al capturar al espectador revelando formas que anhelan para responder cuestiones temporales e históricas, la película de Radu Mihaileanu construye una zona pintoresca que hace un llamamiento para que adopten un comportamiento explícitamente crítico revolucionando las costumbres y tradiciones antiguas y sin clichés. Veamos libres de imaginar nuevas relaciones entre las preguntas y las teorías y prácticas de la acción de vestirse y desvestirse. El flujo y reflujo del proceso creativo impulsado conjuntamente por el autor y el traje.

\section{Referencias Bibliográficas}

Sandel, M. (2012). What money can't buy: the moral limits of markets. New York: FSG, p. 36. Villaça, N. (2012). A Periferia POP na Idade Midia. São Paulo: Estação das Letras e Cores, p. 88 .

(2007). A edição do corpo - tecnociência, artes e moda. São Paulo: Estação das Letras.

\section{Bibliografía}

Bourdieu, P. (2007). A distinção: crítica social do julgamento. RS: Zouk, p. 52.

(2008). A Produção da Crença. RS: Zouk, p.123.

Erengherg, A. (1995). L'invividu incertain. Paris: Calmann-Lévy. 
Godart, F. (2010). Sociologia da Moda. São Paulo: Editora Senac São Paulo, p. 28.

Hall, S. (2008). A Identidade cultural na pós-modernidade. $8^{\mathrm{a}}$ ed. Rio de Janeiro: DP\&A Editora.

Lipovetsky, G. (1989). O Império do efêmero: a moda e seu destino nas sociedades modernas. SP: Companhia das Letras, p. 28.

Sandel, M. (2012). What money can't buy: the moral limits of markets. New York: FSG, p. 36. Simmel, G. (2008). A Filosofia da Moda e outros escritos. Lisboa: Edições Texto e Grafia, p. 27. Svendsen, L. (2010). Moda: uma filosofia. Rio de Janeiro: Zahar, p. 59.

Veblen, T. (2004). A Teoria da Classe Ociosa. Espanha: Fondo de Cultura, p 79.

Villaça, N. (2012). A Periferia POP na Idade Midia. São Paulo: Estação das Letras e Cores, p. 88 .

(2007). A edição do corpo - tecnociência, artes e moda. São Paulo: Estação das Letras. Yonnet, P. (1985). Jeux, Modes et Masses. Paris: Gallimard, p. 307.

Summary: We are used to think about female body seduction from nudity. The body barely covered or with no clothing is a recurrent feature in the construction of the image of the seductive woman. The straps of a dress create a frenzied relationship between skin and fabric representing desires, intentions and feelings, contributing to the plastic conception of the film. Women bodies in the film The fountain of women -directed by the romanian film director Radu Mihaileanu- are dressed and do not want to be seduced by nudity, but under a sex strike, causing a revolution in a small male and conservative community.

Keywords: body - costume - female - plasticity - seductive.

Resumo: É comum pensar na sedução do corpo feminino desde a nudez. A pouca ou nenhuma roupa é recorrente na construção da imagem da mulher a seduzir. Cria-se uma relação frenética entre a pele e o tecido para representar desejos, intenções e sentimentos, contribuindo à concepção plástica de um filme.

Os corpos femininos em A fonte das mulheres, um filme do cineasta russo Radu Mihaileanu, são vestidos e não quere ser seduzido pela nudez, senão em virtude de uma greve de sexo, que provocou uma revolução no pequeno povoado de comunidade machista e ultra conservadora.

Palavras chave: corpo - feminino - plasticidade - traje. 